\title{
Effectiveness of Power Fences on Preventing Human Elephant Conflict in Sri Lanka
}

\author{
Peiris U.K.L. ${ }^{*}$ and Sooriyabandara M.G.C. \\ Department of Wildlife Conservation, Battaramulla, Sri Lanka \\ "lakshman_peiris@ymail.com
}

\begin{abstract}
In view of the availability of land space with the required habitat conditions together with the legal protection, the country is heir to a considerable population of wild elephants. As a result of alteration of land use patterns for development activities the land area enjoyed by the wild elephants for long periods has reduced resulting in Human Elephant Conflict. Surveys carried out by the Department have revealed that there is a loss of about 75 human lives and 170 elephants each year as a result of this conflict. The strategies being adopted so far for preventing the conflict are not totally successful.
\end{abstract}

Semi structured interviews were conducted during January to April 2012 using 240 persons, 34 groups and 93 wildlife officers to identify main reasons for human elephant conflict and assess the efficacy of mitigating measures practiced so far island wide. Efficiency of power fences were assessed using the number of elephant damages before and after the erection of fences in Polonnaruwa wildlife region during 2011 and 2012. The findings have been correlated with the maintenance of the fence and the location of the fence where it has been erected.

Fragmentation of elephant home range, lack of proper land utilisation plans in the rural areas, poor implementation of "elephant conservation plans" identified in national level development projects in EIA process, quantitative and qualitative degradation of elephant habitats, poor adaptation to new conservation activities, lack of community participation are the major reasons that aggravate the conflict.

Establishing Land use plans for every DS divisions, strengthening legal and administrative capacities of existing forest lands, habitat enrichment, population management, awareness of rural community and control of elephant movements are the main effective measures with regard to minimize the conflict.

Erection of power fences is a better solution identified so far. The absence of a proper mechanism for maintenance and erecting fences at wrong locations has caused a problem in further aggravating the conflict. The conflict can be significantly reduced by locating the fence at close proximity to the villages with proper maintenance. For the efficacy, the fence should be clearly visible by either side of it and a fence monitoring mechanism should be established with a daily reporting system.

Keywords: Human elephant conflict, Development, Fragmentation, Home range, Land use plan, Power fences 